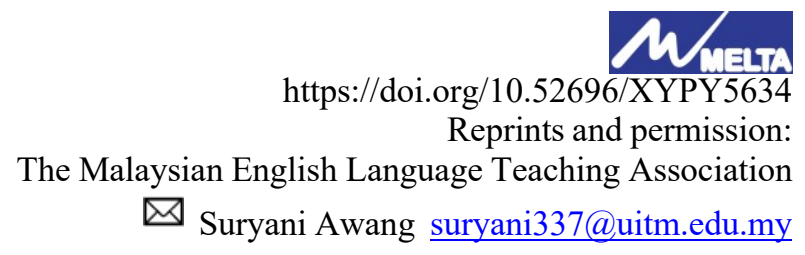

\title{
Social Interaction Strategies among Malay ESL Learners: Preserving Harmony in L2 Oral Communication
}

\author{
Suryani Awang \\ Wan Nuur Fazliza Wan Zakaria \\ Siti Shazlin Razak \\ Akademi Pengajian Bahasa, \\ Universiti Teknologi MARA Cawangan Kelantan, \\ Malaysia
}

\begin{abstract}
Aside from conveying intended messages, maintaining social harmony in oral communication is one of the communicative goals in oral interactions. This could be done by employing Social Interactions Strategies. With English being recognized as a second language (ESL) in Malaysia, the current study seeks to examine how Malay ESL speakers employed such strategies in their conversations and subsequently, maintained social harmony with their interlocutors. The oral data obtained were mapped according to Kumar and Rose's (2010) categories of Social Interaction Strategies namely, Solidarity, Showing Tension Release and Agreeing which are adapted from Bales' (1950) concept of three positive social-emotional interactions. The data were elicited from video-recorded oral interactions in students' role play assessments at one public university in the east of peninsular Malaysia. The results showed the emergence of various types of Social Interaction Strategies that relate to Showing Solidarity, Showing Tension Release and Agreeing. These include showing solidarity by praising and agreeing to other's ideas by showing attention through words of encouragement. Since the respondents consisted of Malay students, the findings led to a suggestion that the use of Social Interactions Strategies did not only promote harmony in their oral interactions but were also in line with the Malays' non-confrontational behaviour as highlighted in past literature. Additionally, the findings also indicated the influence of one's culture and behavioural traits on his or her language use.
\end{abstract}

KEYWORDS: Social Interaction Strategies, L2 Oral Communication, Social Harmony, Malay Values, Non-Confrontational Behaviour

\section{INTRODUCTION}

Malaysia is known for its multi-racial country with the Malays making up more than $50 \%$ out of $69.6 \%$ Bumiputra population while the Chinese and Indians form $22.6 \%$ and $6.8 \%$ of Malaysian population respectively (Current Population Estimates, 2020). Being the largest population in Malaysia, the Malays provide rich data source for research purposes, and hence, have become the 
focus of the current study. In particular, this study aimed to examine the use of Social Interactions Strategies in second language (L2) oral interactions i.e. the English language, among the Malays. The use of such strategies is said to be helpful in maintaining harmony in their conversations. In relation to this, Wan Norhasniah and Mohd Ridhuan (2012) stated that the Malays' characteristics of social relation include tolerant, cooperative, respectful and helpful with each other; all of which are deeply related in the value of "budi" which is defined as "the spiritual foundation that guides the Malays whenever they communicate with others.

Apparently, "budi" emerges from a combination of intellect, feelings and emotions that causes the Malays to continue seeking for positive elements in society (Wan Norhasniah and Mohd Ridhuan Tee, 2012, p. 2662). While "budi" leads to proper language use, this supports what was posited by Kramsch (1998) that one's language use is influenced by their culture. Additionally, "budi" also contributes to non-confrontational behaviour among the Malays (Asrul, 2003). Their social interaction strategies result in many positive implications to individuals and public at large; to the extent that their negotiations led to the country's independence from the British in 1957 (Wan Norhasniah and Mohd Ridhuan Tee, 2012). This clearly shows that "budi", being part of the Malays' cultural values, greatly benefits them. Hence, in the teaching of language in Malaysia, including the English language, such kind of social interaction skills must not be overlooked.

With English being recognized as a second language (ESL) in this country, the current study aimed to examine how Malay ESL speakers employed Social Interaction Strategies in their conversations and subsequently, maintained social harmony with their interlocutors (Marlyna, 2006). All respondents were Malay students studying at one public university in the east coast of peninsular Malaysia.

In particular, the current study aimed to:

1. Identify the use of social interactions strategies in L2 oral interactions

2. Examine how the use of social interaction strategies helped the speakers to maintain harmony in L2 oral interactions.

\section{STATEMENT OF PROBLEM}

While an ability to speak English competently has always been the aim of its learners, the use of English among the Malays in this country can be a challenge or in fact, a problem to some. For one, the English language learners could be taught the language using learning materials from its native countries despite the fact that Malaysians have their own unique cultures. Here, appropriateness of the learning materials and hence, language use could be an issue for the Malays learning English in this country. For instance, the native speakers of English are said to be more direct in their conversations while the Malays tend to be more indirect. Despite this difference however, being indirect is perceived more appropriate, and in fact, more polite among the Malays (Jamaliah, 1995; Asmah, 1992) which in fact, could promote social harmony in oral communication. Apparently, there exists a conflict between ESL learning materials and the expectation of the Malays of being indirect in their communication and hence, maintain social harmony in communication.

Acknowledging the existence of such conflict, the current study was set to examine how the Malay ESL speakers maintain social harmony in their conversations. In this regard, past literature indicates the use of certain strategies in oral interactions that help to maintain harmony among the 
speakers. Such strategies, as proposed by Bales (1950) are known as Social Interaction Strategies. Among advocators of these strategies are Kumar and Rose (2010) who adapted Bales methodology (1950) in their concept of Social Interaction Strategies which became the underpinning theory of the current study.

\section{SIGNIFICANCE OF THE STUDY}

The findings of this current would be useful for ESL speakers in this country to achieve their communicative goals. Candidates of job interviews for instance, would know how to create and maintain harmony in oral interactions and hence, leave positive impressions towards them. Meanwhile, curriculum developers can use the research findings as guiding principles in preparing L2 teaching materials. Here, the learning content could include some suitable L2 cultural elements to help the learners to better engage themselves in the learning process without compromising their own cultural values. As the students move to a higher level, they could be exposed to various communicative situations to expand their horizon in oral communication. Using the various social interaction strategies taught to them, our students are hoped to be able to speak more competently in L2 communication.

\section{LITERATURE REVIEW}

\section{The Malays}

The Malay community is the largest in Malaysia. A review of the past literature indicates that the Malays are known for its non-confrontational behaviour (Asrul, 2003), polite and indirect (Jamaliah, 1995; Asmah, 1992). Overall, they are unassuming people who would try to be "subtle" in their conversation which is done by employing indirectness in order to avoid conflicts (Jamaliah, 1995). The speaker, instead, would go "beating-around-the bush" (Asmah, 1992) before the real intention is conveyed, and even then, is imparted in an indirect way (Kok, 1996). Such attribute is seen rooted from the upbringing of Malay children who are brought up to be seen and not to be heard, and their verbalisation also should not have any indication of "directness" (Asmah, 1992, pp. 174-175). The literature on the Malays describes them as being polite and indirect (Dahlia, 2008; Marlyna, 2006; Lailawati, 2005) which indicates that the Malays place great emphasis on emotional aspects and would do their best to safeguard the feelings of others. Being raised as such might also be the reason for the Malays to be described as conforming to the social responsibilities (Aziz 2001). Apparently, this goes in line with non-confrontational behaviour (Asrul, 2003).

Additionally, Dahlia (2008) quoted other Malay values which include affliation, appreciative, fairness, loyalty, obedience and tolerance while Asrul (2003) added hospitable as another common value among the Malays. Meanwhile, Wan Norhasniah and Mohd Ridhuan Tee (2012) stated that the Malays place high regards to values such as being cooperative, respectful and helpful with each other. Being Muslims, they also emphasize Islamic morality which acts as an effective catalyst for constructing social coexistence and harmony (Bensaid \& Machouche, 2019). All these make up the components of Malay speech convention (Goddard 1997, p. 199) that reflects the Malay identity. Additionally, armed by these traits and values, the Malays assimilate well with other ethnic groups in the country and live harmoniously with them. As stated by Pramela Krish et al. (2012), living in a multi-ethnic country, Malaysians of all ethnic groups would try to develop and maintain harmonious relationships with people around them by identifying themselves with a family, community or organizations. 
Face Concept among the Malays

"Face" generally refers to air muka among the Malays, which, according to Asmah cited in Marlyna (2019), is slightly different from Brown and Levinson's face concept (1978) which they refer to one's want of achieving something in the immediate context of interaction and hence, is closely related to the concept of politeness. Asmah (1996), as cited in Marlyna (2019), particularly believed that air muka in the Malay context covers a broader role in communication as it is always connected to an individual's upbringing, inclusive of influential people in the individual's life such as parents and family members. Similarly, Allwood (2005) also cited in Marlyna (2019) defined air muka as a reflection of one's reputation, good name and honour and hence, should be seriously guarded.

Despite this difference, the Malay culture emphasizes self-restraint in the face of social conflict (Marlyna, 2007) to alleviate conflicts in the occurrence of disagreement. In fact, uttering dissatisfaction or disagreement is less likely to happen among the Malays since they are considered rude and a threat to listener's face and provides potential disrupt to the perseverance of social harmony among the speakers involved (Marlyna, 2007). This clearly shows that the Malays place high regards on preserving one's "face" or air muka which is much needed in establishing good relationships and maintaining social harmony (Marlyna, 2006). In relation to this, a review on past literature indicates the use of Social Interaction Strategies" that helps speakers to create and maintain social harmony in oral communication while delivering their intended messages.

\section{$\underline{\text { Social Interaction Strategies }}$}

Communication has long been recognized as an important aspect of human being. On this, McIver et al. (2003) stated that communication is a fundamental social process needed for individuals to express their thoughts and ideas, and that the ability to communicate is in fact the essence of being human. Successful communication however, is determined by many factors. A study by Rana (2015) showed that nonverbal communication, listening attentively, and the capacity to recognize and understand your own emotions as well as those with whomyou are communicating with, are some characteristics of effective communication. The most essential aspect of effective communication, however, is not what is said, but how it is spoken and the attitude with which the speaker delivers the message (Kelvin-Iloafu, 2016). Additionally, Hall and Pekarek (2004, p. 81) asserted that, successful communication was based on speakers' willingness to cooperate in interactions proficiently.

In helping speakers to communicate successfully, "interaction strategies" have been highlighted as being helpful for speakers (Johnson \& Johnson, 1987). While the use of such strategies helps to avoid any communication breakdown (Kramsch, 1986), its use would be determined by the speaker's language proficiency (Masuda, 2011), hence indicating the differing types of interaction strategies employed by L2 speakers of different language proficiency levels.

The concept of "interaction strategies" has been narrowed down into what is termed as "social interaction strategies" (Bales, 1950; Bejarano et al. 1997; Johnson \& Johnson, 1987; Kumar \& Rose, 2010) which do not only enable active participation (Doughty \& Pica, 1986) but also allow the speakers to acquire better attention during the interactions (Johnson \& Johnson, 1987). Proponents of social-interaction strategies include Bales (1950), Bejarano et al. (1997), Johnson and Johnson (1987) and Kumar and Rose (2010) with each of them viewing the notion in their own perspectives. Johnson and Johnson (1987) for instance, viewed social interaction strategies 
as being helpful to facilitate the flow of conservation, seek for information opinion, rephrase/paraphrase and respond accordingly. Meanwhile, Kumar and Rose (2010) who view the term "social interaction strategies" as being "implemented as instantiations of a conversational behaviour" (Kumar \& Rose, 2010, p.677), were more interested in examining the social-emotional function of such strategies. Examples of social-emotional functions from Kumar and Rose's (2010) perspective are showing solidarity, showing tension release and agreeing.

One recent study on social-interaction strategies was conducted by Krishnan and Maniam (2021) who examined the use of these strategies among L2 learners attending job interviews at an organization. The respondents consisted for 50 candidates from a public university in various disciplines and were shortlisted according to the English placement test based on grammar and writing that was provided by the organization. Semi-structured interviews were conducted involving twenty hiring managers. The interview questions were adopted and modified from the studies of Krishnan et al. (2017) and Zainuddin et al. (2019). The job interview data andperceptions of hiring managers were recorded and transcribed before they were analysed qualitatively using the ATLAS.ti software following Johnson and Johnson's (1987) social-interaction theory. The analysis of social-interaction strategies was categorized based on responses given successful, reserved, and unsuccessful candidates.

The results showed that the use of social-interaction strategies by successful candidates were more pre-emptive compared to the reserved candidates. Upon realizing that they had failed to give appropriate answer, successful candidates would ask for elaborations and at times, rephrase/paraphrase the questions. In contrast, the unsuccessful candidates did not attempt to use any social interaction strategies despite being unable to communicate clearly and failing to comprehend the interview questions. They constantly failed to deliver precise responses that made the interviewer to shift topics as the interaction was not smooth. Meanwhile, the reserved candidates, like the successful ones, did request for elaboration and use rephrasing/paraphrasing. Additionally, they also made several attempts to comprehend the question.

Further analysis on successful candidates showed that speakers with good proficiency usually would be able to use social - interaction strategies. However, some candidates may not be able to understand the questions and this resulted in a few turn-takings in the interactions for message clarifications. Apparently, these findings were supported by Bejarano et al. (1997) who reported that social-interactions strategies reflected the speakers' language proficiency in any communicative context. Similarly, Obiefuna et al. (2015) reported that most of teachers could use interactive strategies due to good proficiency.

Based on their study and review of past literature, Krishnan and Maniam (2021) concluded that those with good proficiency used interactive strategies to have smooth interactions while those with limited proficiency were unable to do so.

While the study by Krishnan and Maniam (2021) focused on the relationship between speakers' language proficiency levels and their use of social-interaction strategies, Kumar and Rose (2010) were more interested in the aspect of social-emotional function of such strategies. Their framework is based on Balesian methodology (Bales, 1950) which categorizes social-interactional strategies in small discussions into four categories namely Positive Social-Emotional Strategies (e.g. 
showing solidarity), Task-Giving Strategies (e.g. giving suggestions), Task-Asking Strategies (e.g. asking for information) and Negative Social-Emotional Strategies (e.g. showing tension).

Based on Bales' (1950) concept of Positive Social-Emotional Strategies which identifies three categories of social interactions namely Showing Solidarity, Showing Tension Release and Agreeing, Kumar and Rose (2010) had mapped the categories to practically implementable conversational strategies in collaborative learning and termed them Social Interaction Strategies as seen in Table 1.

Table 1

Social Interaction Strategies for three social- emotional interaction categories

1. SHOWING SOLIDARITY: Raises other's status, gives help, reward

1a) Do instructions - Introduce and ask names of all participants

1b) Be Protective \& Nurturing - Discourage teasing

1c) Give Re-assurance - When speaker is discontent, asking for help

1d) Compliment / Praise - To acknowledge speaker's contributions

1e) Encourage - When group or members are inactive

1f) Conclude Socially

2. SHOWING TENSION RELEASE: Jokes, laughs, shows satisfaction

2a) Expression of feeling better - After periods of tension, work pressure

2b) Be cheerful

2c) Express enthusiasm, elation, satisfaction - On completing significant steps of the task

3. AGREEING: Shows passive acceptance, understands, concurs, complies

3a) Show attention - To speaker's ideas as an encouragement

3b) Show comprehension, / approval - To speaker's opinions and orientations

Source: Kumar \& Rose (2010)

Referring to Table 1, Kumar and Rose's (2010) Social Interaction Strategies for three socialemotional interaction are divided into three main categories namely Showing Solidarity, Showing Tension Release and Agreeing. Under each category, different types of strategies are stated.

\section{Showing solidarity}

As seen in Table 1, Showing Solidarity which includes raising others' status, giving help and rewarding to others, is divided into six (6) dimensions namely doing introductions, being protective and nurturing (by discourage teasing), giving re-assurance, complementing/praising (acknowledging other's contribution), encouraging and concluding socially. The ultimate idea of doing this is to portray the speaker's effort to build solidarity with the interlocutor.

\section{Showing tension release}

Acknowledging the fact that communication takes place in various contexts, it is important to emotionally control oneself when facing a tensed situation. Under Showing Tension Release, the speaker tries to alleviate tension by joking and laughing with others as well as showing satisfaction. This is done by giving expressions of feeling better after periods of tension and work pressure, being cheerful and expressing enthusiasm, elation and satisfaction on completing significant steps of the task. 
Agreeing

The third category of Agreeing involves strategies employed to show passive acceptance, understanding, concurring and complying. This is done by showing attention to other's idea as an encouragement as well as to show comprehension and approval to one's opinions and orientations.

The above categorizations of social-emotional interaction strategies were originated from Bales' (1950) positive social-emotional interaction strategies. Bales' full framework of social-emotional interaction strategies had earlier been referred to by Kumar et al. (2010) in their study which aimed to describe a socially-capable conversational tutor that supported team of three or more learners in a design task. Conversational tutor in this context was referred to as "autonomous interfaces that interact with students via spoken or written conversation” (Kumar et al., 2010).

The data were collected from interactions between 98 computer-aided engineering students and their human and conversational tutors. The students were placed in three categories; the control group in which the focus was solely on task-based interaction, the social-based group which involved interaction with tutors that were equipped with 11 social interaction strategies listed in Table 1, and the gold standard group in which the students communicated with human tutors. The focus of data analysis was on seven aspects of interactions; doing instructions, being friendly, doing conclusions, trying to release tension, agreeing, pushing and being antagonist.

The results showed that there were significant differences in the first five aspects of socialemotional strategies. The human tutors performed significantly more social turns. On some occasions, the human tutors also performed additional social behaviours that were not part of the social strategies implemented in social tutors. It was concluded that conversational tutors used in collaborative learning scenarios can be improved significantly by making them socially capable while keeping the task (tutoring) related behaviour the same.

A study similar to Kumar et al (2010) was conducted by Fahy (2005) who examined "communication functions" that occurred in online vs face-to-face interactions. Using the same framework by Bales (1950), the data analyzed were the text of a 13 -week online distance delivered graduate course at Canadian university. As for online data, the students participated in an online conference as an assignment in the course, worth $10 \%$ of the final grade.

Analysis of data based on Bales' group interaction framework (1950) showed that the online group reflected high levels of presence and control by the instructor. The students also engaged with the environment of critical inquiry provided by the instructor. More importantly, the online group also maintained high levels of harmony by demonstrating markedly less disagreement than other some observed online interactions. This, according to Fahy (2005), could be due to the clear presence and regular involvement of the instructor that might have influenced the interactions. It was then concluded that online communication more or less resembled the face-to-face group but also differed subtly from face-to-face groups studied by Bales.

It is worth highlighting at this point that the above classifications of social interaction strategies given in Table 1 is contextualized in oral interactions between members involved in collaborative learning. It should be noted however, that maintaining social harmony also occurs in a written discourse as highlighted by Abbas (2013). In his analysis on a fiction entitled Anne of Green Gables, Abbas adopted Brown and Levinson's (1978) theory of politeness to account for the 
linguistic strategies in addition to some subsequent contribution by Spencer-Oatey (2002) to account for sociality rights and obligations. The findings indicated that the main character, Anne Shirley tried her best to establish common grounds to achieve friendly and harmonious relationships with others.

The tendency to make efforts that bring about social harmony indeed extends beyond in collaborative learning and literary discourse. Fakhri et al. (2018) for instance, examines interethnic relations involving people in Kisaran City, Asahan Regency in Indonesia. His data were gathered from interviewing people living in inter-ethnic society. The result indicated that people in Kisaran had had close relationship between different ethnic groups due to economic activities such as trade and migration, resulting in the people being open, democratic, tolerant and full of willingness; all of which coexist in society. This has spawned multiculturalism that is the hallmark of civilization of Kisaran. Undoubtedly, the people become inherently dynamic and are always open to changes in the process of creating and maintaining social harmony.

Based on the above, social harmony is undoubtedly an important element in human communication; be them in a small context such as collaborative learning or in a bigger scope that it can even lead to a society's civilization. The positive impact of social harmony is far reaching, hence making this study a worthwhile effort.

\section{METHODOLOGY}

This qualitative study was conducted to examine how social harmony was maintained by speakers in L2 interactions. It employed Kumar and Rose's (2010) perspective of social interactions strategies mainly because the framework focuses on the emotional aspects of speakers. Apparently, the framework goes line with Malay cultural values which place high regards on safeguarding the feelings of others as reflected in their polite and indirect behaviours. Additionally, the three categories proposed by Kumar and Rose (2010) namely, Showing Solidarity, Showing Tension Release and Agreeing promote harmony in communication. No matter how serious or critical the context of interaction is, the act of re-assuring others who are doubtful in order to show solidarity, laughing together to show tension release and agreeing to others, would bring about positiveness and harmony in interactions.

More specifically, the current study was set to identify the use of social interactions strategies in L2 oral interactions and further, examine how the use of such strategies helped the speakers to maintain harmony in L2 oral interactions. The rationale behind selecting the Malays as the respondents in this study was the assertion by Abdullah and Wong (2006) that Malays who constitute more than half of the country population were described as being the least receptive to the use of English. Considering this, it would be interesting to find out whether the Malays could function in L2 interactions and employ any strategies to maintain social harmony in the interaction. Similarly, it would also be interesting to find out how such strategies helped to bring about social harmony in the interactions despite the speakers' lack of competency in using the language.

In achieving these objectives, observations on role-play assessments for Integrated Language Skills (ELC121) were carried out at one public university in the east coast of peninsular Malaysia. The role-play is part of the course assessment for part one students at diploma level and carries $15 \%$ of the total grade. This role play presentation is performed in pairs for 5 minutes after 5 minute preparation based on one specified theme given by the researchers who were also the 
instructors in the class (the theme is referred to as Situation). In total, 15 pairs of students performing role-play assessments were observed and video-recorded but for the purpose of this study and its data analysis, only eight pairs of students were analysed in detail, mainly because, their use of social interaction strategies were rather obvious compared to other pairs. It should also be noted that out of five (5) informal situations available, only four (4) situations were highlighted for the same reason.

\section{Sampling}

The current study employed convenience technique of sampling which involves drawing samples that are both easily accessible and willing to participate in a study (Teddlie \& Yu, 2007), hence making data collection an easy choice for researchers (Latham, 2007). The study was localized at one public university in the east coast of peninsular Malaysia involving students from different majors who registered for Integrated Language Skills 1 (ELC121) course in which role play assessment is conducted as part of the course assessment. Being part one students, their age ranged between 18 to 20 years. For the purpose of this study, the eight pairs were marked as Pairs A to H.

\section{Data Collection Procedures}

This qualitative study involved observations on a group of ELC121 students performing role-play assessments in pairs as part of Integrated Language Skills (ELC121) course evaluation. To initiate this oral task, the participants were given five minutes to prepare the responses to a situation given by the researchers while the other five minutes were given for them to act out the role-play in pairs. The task given was on one specified situation randomly selected by the researchers (see Appendix 1). Each situation varies in terms of theme but all of them revolve around informal setting.

In order to facilitate the researchers in the data analysis later, the role-play sessions were videorecorded before the oral data were transcribed in a verbatim form to allow full understanding of the conversations. Upon completing the transcriptions, the recordings were observed again. This time, the researchers cross checked the interactions with the transcription to identify the use of social interaction strategies. The types of strategies that emerged from the data were then mapped against Kumar and Rose's perspective of Social Interaction Strategies (2010) and their number of frequencies was calculated.

\section{Data Analysis}

The collected data were analysed using content analysis anchored in Kumar and Rose's perspective of Social Interaction Strategies (2010) which identifies three positive social-emotional interaction categories; Showing Solidarity, Showing Tension Release and Agreeing. It started with identification of social interaction strategies employed by the students before the data were further examined to see how the strategies brought about harmony in the interactions.

Under each category of Social Interaction Strategies, there are various strategies as stated in Table 1. For instance, in utterances that indicate Solidarity, the strategies could involve praising others or giving them re-assurance in some matters which help to make the latter feel at ease in the conversations. Similarly, Agreeing, as one of social-emotional interaction categories is an indication of the speakers' passive acceptance, understanding or attention. All these bring about positive vibes in the interactions. 
Upon identifying the occurrence of social interaction strategies in the role-play assessments by all pairs (Pairs A to $\mathrm{H}$ ), the strategies that emerged were then classified based on the categories stipulated in Kumar and Rose's Social Interaction Strategies (2010) while the utterances were labelled based on which pairs they were extracted from and then, given an excerpt number. The findings were then tabulated according to the situation number.

\section{RESULTS AND DISCUSSION}

Discussion in this section is organized in the following manner. First, the situations in which the students were engaged are described and numbered as either Situations 1, 2,3 or 4. This is followed by the presentation of research findings as seen in Tables 2, 3, 4 and 5. Notice that some excerpts were purposely written at length so as to ensure a comprehensive understanding of the subject matter being talked about. Since the role-play assessments were conducted in pairs, there were two speakers in each pair, marked as either Speaker A or B. While the first column of these tables indicates the pairs from which the excerpts were extracted from, the second column contains utterances in which social interaction strategies were employed (bold form). Finally, the types of social-emotion interactions which correspond to the students' utterances are stated in the last column. This section then ends with a discussion on how the use of social interaction strategies help to maintain harmony in L2 interactions.

Situation 1: Two roommates are planning for activities to do during their leisure time. One of them suggested playing an outdoor game while the other think that they should play an indoor game. Act out the conversation that takes place at their hostel.

Table 2

Social Interaction Strategies in Excerpts from Situation 1

\begin{tabular}{|c|c|c|}
\hline & Expressions & $\begin{array}{l}\text { Social Interaction Strategies } \\
\text { based on social- emotional } \\
\text { interaction categories }\end{array}$ \\
\hline \multirow{9}{*}{$\begin{array}{l}\text { Pair B } \\
\text { Excerpt } 1\end{array}$} & A: I prefer to play outdoor game as it can benefit our & \\
\hline & $\begin{array}{l}\text { leisure time during weekend rather than staying in our } \\
\text { room. }\end{array}$ & \\
\hline & $\begin{array}{l}\text { B: Yes, I agree with that...erm... but indoor games } \\
\text { can challenge our brain }\end{array}$ & $\begin{array}{l}\text { SAgreeing: Shows passive } \\
\text { acceptance, understands }\end{array}$ \\
\hline & $\begin{array}{l}\text { A: Erm.. maybe, but I prefer indoor game... err.. } \\
\text { outdoor game (making correction) because outdoor }\end{array}$ & \\
\hline & game can benefit our time and it can make ours ...it can & \\
\hline & make our bodies healthy as we have a lot of movements & \\
\hline & during outdoor game ...during playing outdoor games. & \\
\hline & B: Aaa... I agree with that. I ... I think indoor and & \\
\hline & $\begin{array}{l}\text { outdoor games have their own benefit. Why [don't] we } \\
\text { try both of them. }\end{array}$ & $\begin{array}{l}\text { Agreeing: Shows passive } \\
\text { acceptance, understands }\end{array}$ \\
\hline \multirow[t]{3}{*}{ Excerpt 2} & $\begin{array}{l}\text { B: We can,. We can go to the library for.. for gaming } \\
\text { and also...also we can install games in our phones for } \\
\text { spending my time. }\end{array}$ & \\
\hline & $\begin{array}{l}\text { A: Oo.. like...like you used to play candy crush in your } \\
\text { phone. }\end{array}$ & \\
\hline & B: Yes... and Ten Ten games (laughing) & Showing Tension Release: \\
\hline
\end{tabular}




\begin{tabular}{ll}
\hline & A: Ten Ten games? (laughing). I think that's Walin's Jokes, laughs \\
& favourite, right? \\
\hline Pair G & B: ... because I'm so...so great when I'm playing it \\
Excerpt 1 & (referring to badminton). \\
& A: Ouh! I heard that you are...your... \\
& B: Participate... \\
& A: Ya... Participate in your school... in our school \\
& B: Yes, old school, now we at UiTM right? \\
\hline Excerpt 2 & B: So, conclusion is we have to choose or not. Oh no! \\
& May be another [indoor game]...may be \\
& A: Erm... what kind of game? Puzzle game! \\
& B: Yaa... you are good [at] puzzle game, right? [I] Showing Solidarity: Praise \\
& always fail when I do that game. \\
\hline Excerpt 3 & A: Aaa.. I heard that you like Sudoku \\
& B: Yes, I'm so... [I] really [like]. That's why I got A+ \\
& [for] my Calculus. \\
A: Ouh! So proud of you. Can you teach me Calculus Showing Solidarity: Praise \\
then?
\end{tabular}

In Situation 1, two roommates were considering either to do outdoor or indoor activities during their leisure time. Referring to Table 2, it was found that speaker B in Pair B firstly expressed her agreement to Speaker A's statement that playing an outdoor game during weekend was more beneficial than staying at home before giving her own stand that indoor games, as opposed to outdoor games, are good to challenge one's brain. Speaker A then expressed her agreement to B's statement that indoor game can challenge our brain, but for some reasons, she would still opt for outdoor games. The interactions then continued until speaker B admitted that both types of games were beneficial in their own way. In these interactions, both speakers indicated their acceptance and understanding towards each other despite having their own stands with regards to the benefits of outdoor and indoor games. Apparently, both speakers felt at ease during the interactions although they both had different opinions in choosing which game to play in their leisure time.

In Table 2, we also notice that, unlike Agreeing and Showing Tension Release which occurred only once, Showing Solidarity occurred thrice, hence, indicating its dominance in the speakers (twice in Speaker B and once in Speaker A) engaged in Situation 1. Showing Solidarity came in the form of giving help as seen in Excerpt 1 of Pair G (offering the word "participate") and praising others as seen in Excerpts 2 and 3 also of Pair G ("you are good [at] puzzle game, right?" and "Ouh! So proud of you"). Meanwhile, Showing Tension Release occurred in the form of cracking jokes and laughing with others as seen in Excerpt 2 of Pair B.

Situation 2: You noticed that your best friend always skips his/her breakfast. He/She suffers from gastritis which makes him/her feels a burning pain in the stomach. This poor health condition distracts his/her attention in class. As a friend, advise him/her on the importance of having breakfast every day. Act out the scene that takes place in the classroom.

Table 3

Social Interaction Strategies in Excerpts from Situation 2

\begin{tabular}{ll}
\hline \multirow{2}{*}{ Expressions } & Social Interaction \\
Strategies based on \\
\hline
\end{tabular}




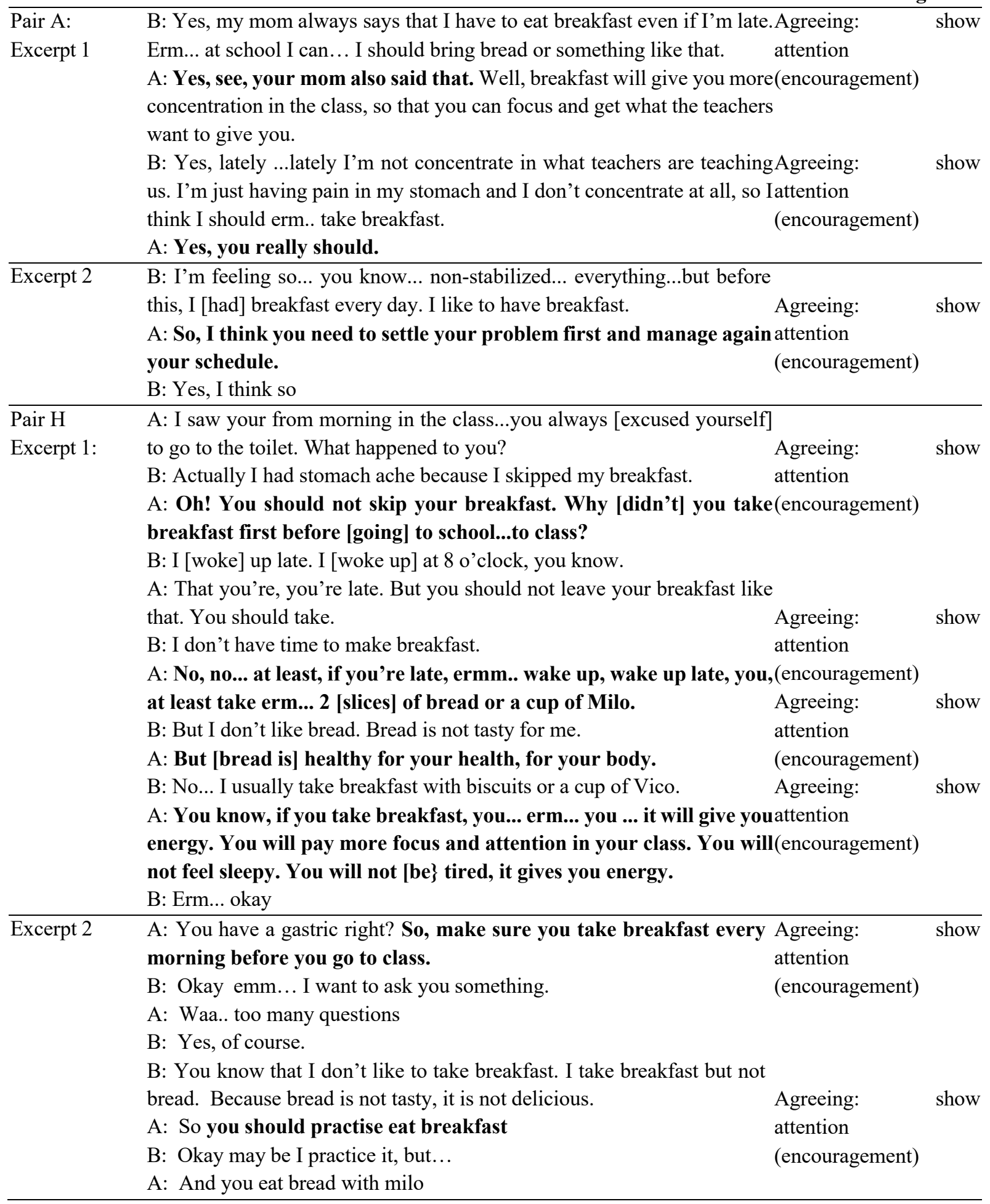

Unlike the pairs given Situation 1 which employed various types of social interaction strategies (Agreeing, Showing Tension Release and Solidarity), all pairs given Situation 2 employed one type of Social Interaction Strategies, namely "Agreeing" by showing their attention as indicated 
by their words of encouragement. This is seen in Excerpts 1 and 2 of Pair A as well as Pair H. The words of encouragement are as follow:

"Yes, see, your mom also said that" and "Yes, you really should” (Speaker A in Excerpt 1 of Pair A).

"So, I think you need to settle your problem first and manage again your schedule" (Speaker A in Excerpt 2 of Pair A).

Many other words of encouragement could be seen in Excerpts 1 of Pair $H$ as seen below:

"Oh! You should not skip your breakfast. Why [didn't] you take breakfast first before [going] to school...to class?"

"No, no... at least, if you're late, ermm.. wake up, wake up late, you, at least take erm... 2 [slices] of bread or a cup of milo".

"But [bread is] healthy for your health, for your body".

"You know, if you take breakfast, you... erm... you ... it will give you energy. You will pay more focus and attention in your class. You will not feel sleepy. You will not [be\} tired, it gives you energy".

In Excerpt 2 of the same pair (Pair H), the same speaker (Speaker A) uttered more words of encouragement as seen below:

"So, make sure you take breakfast every morning before you go to class".

"So you should practise eat breakfast".

From all their words of encouragement, both Speakers A in Pairs A and H managed to show their attention on their partners by indicating agreement in what was being discussed (that one should take breakfast from class) through words of encouragement.

Situation 3: You are discussing a wedding preparation with your cousin. He/She plans to have a grand, luxurious wedding ceremony as he/she is the eldest child in the family. Advise him/her to be moderate or reasonable in the preparation. Act out the scene that takes place at a one-stop wedding exhibition.

Table 4

Social Interaction Strategies in Excerpts from Situation 3

\begin{tabular}{|c|c|c|c|}
\hline & Expressions & $\begin{array}{l}\text { Social } \\
\text { Strategies } \\
\text { social- } \\
\text { interaction c }\end{array}$ & $\begin{array}{l}\text { Interaction } \\
\text { based on } \\
\text { emotional } \\
\text { categories }\end{array}$ \\
\hline $\begin{array}{l}\text { Pair D } \\
\text { Excerpt } 1\end{array}$ & $\begin{array}{l}\text { B: Yes, may be and it's quite ... you have to find a not too expensive, } \\
\text { because you are going to ... you are going to... you are going to... you } \\
\text { are going to pay many other ...other things of the... the place, the } \\
\text { wedding, dress...ya } \\
\text { A: So, thanks for the advice and for your suggestion. Erm... I } \\
\text { would love it emm... and how lovely to see you. } \\
\text { B: Ya, me too. It was ...haven't seen you for ages and I feel great to } \\
\text { see you. }\end{array}$ & $\begin{array}{l}\text { IShowing } \\
\text { Praise } \\
\text { e }\end{array}$ & solidarity: \\
\hline $\begin{array}{l}\text { Pair E } \\
\text { Excerpt } 1\end{array}$ & $\begin{array}{l}\text { B: I'm thinking about the grand, luxurious with gold black theme ... } \\
\text { [do] you agree with that? I think it [looks] nice. } \\
\text { A: Erm... I agree with that, but erm...I'm sorry because I think it is... I } \\
\text { think for you...erm... eh you are...you are... you [are] the eldest child }\end{array}$ & & \\
\hline
\end{tabular}


in the family, right? So I think, my recommendation is, you should

think about the other siblings first... and...

B: I understand what you want to say, but this is the first and the Agreeing:

last of ...in my entire life you know...it's my, it's my wedding. understands

Shows A: But Nadia, you know that yours...your younger sister is studying..

\begin{tabular}{lll}
\hline Excerpt 2 & A:If that is the case, I think you can invite many people & Showing solidarity: Gives \\
but your wedding erm... apa nak cakap... & help \\
B: Limit? & A: Aaa... limit. \\
B: I think you said the limit & A: Aa... yes, limit.
\end{tabular}

In Excerpt 1 of Situation 3, Speaker A was asking for her cousin's (Speaker B) opinion about her wedding plan. After receiving her response, the former showed that she acknowledged her cousin's contribution by responding:

"thanks for the advice and for your suggestion. Erm... I would love it emm... and how lovely to see you".

Such response that indicated solidarity between the two speakers did not only make Speaker B felt appreciated, but also created harmony in the conversation despite the fact that Speaker B's response actually contradicted to Speaker A's original plan.

Another social interaction strategy employed in Situation 4 is seen in Excerpt 1 of Pair E in which Speaker B indicated her agreement by understanding as seen in the following utterance:

"I understand what you want to say, but this is the first and the last of ... in my entire life you know...it's my, it's my wedding."

In another Excerpt by the same pair, Speaker B showed solidarity by offering the word "limit" that did not come across Speaker A's mind. We notice here that Speaker B also showed her understanding and offered help for Speaker A.

Situation 4: Two travel mates are planning for a vacation in Indonesia. One of them suggests hiring the service of a travel agency to get the best offer while the other prefers to travel independently to save money. Act out the conversation that takes place at the office.

\section{Table 5}

Social Interaction Strategies in Excerpts from Situation 4

\begin{tabular}{|c|c|c|}
\hline & Expressions & $\begin{array}{l}\text { Social Interaction } \\
\text { Strategies based on } \\
\text { social- } \\
\text { interaction categories }\end{array}$ \\
\hline $\begin{array}{l}\text { Pair C: } \\
\text { Excerpt } 1\end{array}$ & $\begin{array}{l}\text { A: Ermm.. we have not seen each other for.. for two months.. err, } 1 \\
\text { month } 2 \text { weeks, right? } \\
\text { B: Ya, } \\
\text { A: Actually I [took] emergency leave because my mon [is] sick, and } \\
\text { now, praise to God, she'll [be] fine. .. she [is] fine and ... } \\
\text { B: (Interrupt) She will be fine. }\end{array}$ & \\
\hline
\end{tabular}




\begin{tabular}{|c|c|c|}
\hline & $\mathrm{A}: \mathrm{Ya}$ & $\begin{array}{l}\text { Showing solidarity: } \\
\text { gives re-assurance }\end{array}$ \\
\hline Excerpt 2 & $\begin{array}{l}\text { A: Erm.. talking about travel agency... I think...I...I...got a frienc } \\
\text { that work in Indonesia...that work with travel agency [in] Indonesia } \\
\text { So, I think I can contact him [referring to celebrity Randy } \\
\text { Pangalela]... Whatsapp him and who knows we can get a discount. } \\
\text { B: Ya.. that's really great!...that's really great! So, sorry I'm so } \\
\text { excited actually. } \\
\text { A: Ya, me too. Ermm... so, Indonesia. Can we meet Randy Pangalela } \\
\text { there? } \\
\text { B: Randy Pangalela? I don't think so. } \\
\text { A: You know, I admire him the most, you know. } \\
\text { B: So we're going there with travel agency, right? } \\
\text { A: Erm... travel agency... } \\
\text { B: No worries, we [won't] be lost, if we have...ya } \\
\text { A: But, we go two of us? Only two of us } \\
\text { B: Oh no... my friends will follow us too. There's ...ya, I invite some } \\
\text { of my friends, my cousins. So, [there'll] be a lot of people that wil } \\
\text { come with us. }\end{array}$ & $\begin{array}{l}\text { Showing solidarity: } \\
\text { gives re-assurance } \\
1\end{array}$ \\
\hline $\begin{array}{l}\text { Pair F: } \\
\text { Excerpt } 1\end{array}$ & $\begin{array}{l}\text { B: I trust, I really trust the agency because most of us... most } 0 \\
\text { people...already...already...already } \\
\text { A: Already go, already went [for] the vacation } \\
\text { B: Through the agency } \\
\text { A: Yes, through the agency. I think that you...you have prepared al } \\
\text { the things, right? } \\
\text { B: Right...ermm yes. }\end{array}$ & $\begin{array}{l}\text { f Showing } \\
\text { gives help }\end{array}$ \\
\hline
\end{tabular}

Unlike the earlier utterances that incurred in Situations 1-3 which revolve Agreeing and Showing Solidarity, utterances engaged in Situation 4 involve giving re-assurance to the interlocutor's earlier statement about their plan for a vacation in Indonesia (see Excerpts 1 and 2 of Pair C in Table 5). This occurred at the beginning of their interactions when Speaker A expressed her concern over her mother's health condition. While she was hopeful for her mother's recovery, Speaker B interrupted her by saying "she will be fine". The strategy of giving re-assurance worked well to show solidarity between the two speakers.

In another instance, Speaker A of Pair C explained what she had prepared for their vacation including the possibility to meet Indonesian celebrity Randy Pangalela. Upon knowing this, Speaker B jumped in excitement by saying "that's really great!...that's really great!" Here, the praise goes to Speaker A for her good job in making the plan. Solidarity is evident here.

As they continued with their conversation, Speaker A expressed her concern about visiting Indonesia as seen in Excerpt 2. To convince her, Speaker B responded, 'No worries, we [won't] be lost". This should make Speaker A feel assured that their decision to use travel agency service to visit Indonesia was a correct decision.

Finally, in Pair F's Excerpt 1 of Situation 4, Speaker B's solidarity towards Speaker A was evident when the former helped the latter who stumbled her sentence by suggesting the words "through the agency". This was fully accepted by Speaker A as she responded "Yes, through the agency". 
Based on the research findings presented above, the types of social interaction strategies and their number of occurrences are presented in Table 6.

\section{Table 6}

Frequency number of the Use of Social Interaction Strategies for three social-emotional interaction categories based on Kumar \& Rose (2010)

1. SHOWING SOLIDARITY: Raises other's status, gives help, reward

3

1a) Do instructions - Introduce and ask names of all participants

1b) Be Protective \& Nurturing - Discourage teasing

1c) Give Re-assurance - When speaker is discontent, asking for help

1d) Compliment / Praise - To acknowledge speaker's contributions

1e) Encourage - When group or members are inactive

1f) Conclude Socially

2. SHOWING TENSION RELEASE: Jokes, laughs, shows satisfaction

2a) Expression of feeling better - After periods of tension, work pressure

2b) Be cheerful

2c) Express enthusiasm, elation, satisfaction - On completing significant steps of the task

3. AGREEING: Shows passive acceptance, understands, concurs, complies

3a) Show attention - To speaker's ideas as an encouragement

3b) Show comprehension,/ approval - To speaker's opinions and orientations

TOTAL NUMBER OF USE

Source: Kumar \& Rose (2010)

Referring to Table 6, the total number of social interaction strategies employed by the respondents of this study is 22. Among these types of strategies, Showing Attention by agreeing to the idea (of taking breakfast before going to class) and then giving words of encouragement occurred nine (9) times. The next frequently employed strategy is Showing Solidarity by praising which occurred four (4) times. This is followed by giving help, also to show solidarity and showing passive acceptance as a form Agreeing which occurred thrice. Meanwhile, Giving Re-assurance to show solidarity twice while Laughing that helps to show Tension Release occurred once. Undeniably, all these strategies help to create a pleasant atmosphere for both speakers in all situations.

While the above results were obtained from face-to-face interactions conducted in the current study, it is important to note that social-emotional interactions strategies also occurred in online interactions as evident in studies by Kumar et al. (2010) and Fahy (2021). In Kumar et al. (2010), when comparisons were made between task-based group, social-based group and gold standard group which utilized human tutors, it was found some human tutors performed additional social behaviours that were not part of the social strategies implemented in social tutors. This indicates that there is still room for improvement for tutors in task-based and social-based groups.

Driven by the above statement, it is therefore imperative that social-emotional interaction strategies are taught to our students so that they will be able to engage in more effective conversations. By paying close attention to the emotional aspect of their interlocutors, all speakers will be moved towards promoting social harmony in their society.

Suryani, A., Wan Nuur Fazliza, W.Z., \& Siti Shazlin, R. (2021). Malaysian Journal of ELT Research, Vol. 18(2), pp. 48-68 


\section{CONCLUSION}

The data analysis shows that the Malay ESL speakers in this study made enough effort to maintain harmony in their L2 oral interactions by employing various types of social interaction strategies. The data analysis indicated that the students showed solidarity through strategies such as praising others, giving help as well as acknowledging others' contributions. Additionally, giving words of encouragements were found abundantly in the data aside from laughing with their role-play partner to create a harmonious atmosphere. All these support Wan Norhasniah and Mohd Ridhuan (2012) in which the Malays' characteristics of social relation include tolerant, cooperative, respectful, and helpful with each other. From the use of these strategies, the Malays can maintain their roots of being non-confrontational as highlighted by Asrul (2003).

In a nutshell, the findings of this study showed that not only the Malays could function well in L2 communication, but also supported what was posited by Kramsch (1998) that one's culture and behavioural traits influence their language use. Hence, we have no reason to worry that Malaysian L2 learners would be influenced by the foreign materials they are exposed to in learning English since their cultural and behavioural traits remain strong in them.

As showed in this study, the Malays who are the ESL learners in this country function well in the language. Their Malay cultural traits which promote harmony in communication are even portrayed through their use of social-emotional interaction strategies in their L2 communication. Living in a multi-racial country like Malaysia, it is important that this is retained among Malaysian citizens. One of the ways to ensure this is by embedding social-emotional interaction strategies in English language curriculum. Since Fahy (2005) had shown that online interactions somehow resembled face-to-face interactions, the mode of teaching should not be an issue. In the digital era we are living now, learning activities can take place in various forms with the use of numerous learning platforms. Learners could be assigned groupwork that requires minimal preparation so as to train them to function in the real world. The tasks given should prompt them to interact appropriately with others by considering the context of interactions while safeguarding their face. At the same time, learners could be exposed to various social-emotional interaction strategies that promotes social harmony.

Despite this however, it should be noted that the ability to use social-emotional interaction strategies is dependent on learners' language proficiency levels (Krishnan \& Maniam, 2021; Masuda, 2011). Teachers are therefore expected to be more creative in assigning tasks for students that would cater for their ability while at the same time, help to improve their language proficiency level. Getting the weaker students to work with the more proficient ones could be an alternative since the former would be trained to put their best effort so that they would be part of the group members. The group the students join in a class may just be part of a small community they live in. As their language progresses, they would be able to function in a larger community while maintaining social harmony.

\section{ACKNOWLEDGMENT}

The authors would like to thank Universiti Teknologi MARA for its financial support granted under 600- IRMI/DANA 5/3/ARAS. 


\section{REFERENCES}

Abbas, N. F. (2013). Positive politeness \& social harmony in Literary Discourse. International Journal of Applied Linguistics \& English Literature, 2(3), 186-195.

Abdullah, M. H., \& Wong, B. E. (2006). Listening to the ethnic voice in ESL learning. The English Teacher, 12, 15-26.

Asma Abdullah. (1996). Going Glocal: Cultural Dimension in Malaysian Management. Kuala Lumpur: MIM, 129-132.

Asmah Haji Omar. (1992). The Linguistic Scenery in Malaysia. Kuala Lumpur: Dewan Bahasa dan Pustaka.

Asrul, Z. (2003). The Malay Ideals. Kuala Lumpur: Golden Books Centre.

Bales, R.F. (1950). A set of categories for the analysis in small group interaction. American Sociological Review, 15(2), 257-263.

Bejarano, Y., Levine, T., Olshtain, E., \& Steiner, J. (1997). The skilled use of interaction strategies: Creating a framework for improved small-group communicative interactionin the language classroom. Elsevier Science, 25(2), 203-214.

Bensaid, B., \& Machouche, S. (2019). Muslim morality as foundation for social harmony. Journal Al-Tamaddun, 14(2), 51-63.

Brown, P. \& Levinson, S. (1978). Universals in language use: Politeness phenomena. In Goody, E. N. (eds.). Questions and Politeness, pp. 56-289.

Current Population $\quad$ Estimates. (2020). Retrieved from https://www.dosm.gov.my/v1/index.php?r=column/cthemeByCat\&cat=155\&bul_id=OV ByWjg5YkQ3MWFZRTN5bDJiaEVhZz09\&menu_id=L0pheU43NWJwRWVSZklWdz Q4TlhUUT0.

Dahlia Zawawi. (2008). Cultural dimensions among Malaysian employees. International Journal of Economics and Management, 2(2), 409-426.

Doughty, C., \& Pica, T. (1986). Information-gap tasks: Do they facilitate second language acquisition? TESOL Quarterly 8 (1), 305-324.

Fahy, P.J. (2005). Online and face-to-face group interaction processes compared using Bales' Interaction Process Analysis (IPA). European Journal of Open, Distance and E-Learning $9(1)$.Retrieved from https://old.eurodl.org/? $p=$ archives \&year $=2006 \&$ halfyear $=1 \&$ article $=216$

Fakhri, M.S., Amsani, H., \& Hajar, I. (2018). Social harmony in the inter-ethnic relations (A study in society multiculturalism in Kisaran). Advances in Social Science, Education and Humanities Research, 136, 379-383.

Goddard, C. (1997). Cultural values and "cultural scripts" of Malay (Bahasa Melayu). Journal of Pragmatics, 27(2), 183-201.

Hall, J. H, \& S. K. Doehler (2011), L2 interactional competence and development, 1-18. Multilingual Matters.

Jamaliah Mohd Ali. (1995). The pragmatics of cross-cultural communication in a Malaysian context. Rules of Speaking: Verbal intereactions at play, 112-124. 
Johnson, D. W., \& Johnson, FP. (1987). Joining together group theory and group skills. PrenticeHall Inter- national, Inc.

Kelvin-Iloafu, L. E. (2016). The role of effective communication in strategic management of organizations. International Journal of Humanities and Social Science, 6(12), 93-99.

Kok, S. T. (1996). The acquisition of Malay as a second language: Acase of the essentiality of culture learning. September, 6(2009), 365-388.

Kramsch, C. (1986). From language proficiency to interactional competence. The Modern Language Journal, 70(4), 366-372.

Kramsch, C. (1998). Language and Culture. Oxford: Oxford University Press.

Krishnan, I.A. \& Maniam, M. (2021). An analysis of Social-Interaction Strategies in job interviews amongst fresh graduates. International Journal of Academic Research in Business and Social Sciences, 11(10), 742-760.

Krishnan, I. A., Ramalingam, S. J., Hee, S. C., \& Maruthan, E. (2017). The selection practices and recruitments of fresh graduates in local organisation's job interview. Journal of Language and Communication, 4(2), 153-116.

Kumar, R., \& Rose, C. P. (2010). Engaging learning groups using Social Interaction Strategies. Human Language Technologies: The 2010 Annual Conference of the North American Chapter of the ACL, 677-680.

Kumar, R., Ai H., Beuth J.L., \& Rose C.P. (2010). Socially-capable conversational tutors can be effective in collaborative learning situations. In International conference on intelligent tutoring systems, 156-164.

Lailawati Mohd Salleh. (2005). High/low context communication: the Malaysian Malay style. Proceedings of the 2005 Association for Business Communication Annual Convention, 111.

Latham, B. (2007). Sampling: What is it Quantitative Research Methods-Texas Tech University. https://pdfs.semanticscholar.org/0d03/d40034b1b217824b1ed8d8c98daf537f0598.pdf

Marlyna Maros. (2019). Cultural values in Malay speech acts. Sintok: UUM Press.

Marlyna Maros. (2007). The social functions of complaints in a Malay speech community. Proceedings of $17^{\text {th }}$ Annual Conference of the Southeast Asian Linguistics Society (SEALS).

Marlyna Maros. (2006). Apologies in English by adult Malay speakers: Patterns and competence. International Journal of Language, Culture and Society, 19, 1-14.

Masuda, K. (2011). Acquiring interactional competence in a study abroad: Language learners'use of the interactional particle ne. The Modern Language Journal, 95(4), 519-540.

McIver, Jr.,W.J., Birdsall, W.F. \& Rasmussen, M. (2003). The internet and the right to communicate. Paper presented at EURICOM 2003 Conference, Padua \& Venice, Italy. 37 May 2003.

Obiefuna, C. A., Offorma, G. C., \& Ifegbo, P. C. (2015). Perception of intern teachers' use of interactive strategies in teaching large classes in online environment. InternationalOnline 
Social Interaction Strategies among Malay ESL Learners

Journal of Education and Teaching (IOJET), 2(3), 146- 156.

Pramela, K., Marlyna Maros \& Siti Hamin Stapa. (2012). Sociocultural factors and social presence in an online learning environment. GEMA Online Journal of Language Studies, 12(1), 201213.

Rana, M. P. (2015). Effective communication skills. IJRAR-International Journal of Research and Analytical Reviews, 2(1), 29-31.

Spencer-Oatey, H. (2002). Managing rapport in talk: Using rapport sensitive incidents to explore the motivational concerns underlying the management of relations. Journal of Pragmatics, 34(5), 529-545.

Teddlie, C., \& Yu, F. (2007). Mixed methods sampling: A typology with examples. Journal of Mixed Methods Research, 1(1), 77-100.

Wan Norhasniah Wan Hussin \& Mohd Ridhuan Tee Abdullah (2012). Social Relation between the Malays and Chinese Communities from a Civilizational Perspective. International Journal of Social, Behavioral, Educational, Economic, Business and Industrial Engineering, 6(10), 2661-2666

Zainuddin, S. Z., Pillai, S., Dumanig, F. P., \& Phillip, A. (2019), English language and graduate employability, Education + Training, 61(1), 79-93. 


\section{APPENDIX 1}

The five situations performed by the participants of the role-play assessment:

Situation 1: Two roommates are planning for activities to do during their leisure time. One of them suggests playing an outdoor game while the other thinks that they should play an indoor game. Act out the conversation that takes place at their hostel.

Situation 2: You noticed that your best friend always skips his/her breakfast. He/She suffers from gastritis which makes him/her feels a burning pain in the stomach. This poor health condition distracts his/her attention in class. As a friend, advise him/her on the importance of having breakfast every day. Act out the scene that takes place in the classroom.

Situation 3: You are discussing a wedding preparation with your cousin. He/She plans to have a grand, luxurious wedding ceremony as he/she is the eldest child in the family. Advise him/her to be moderate or reasonable in the preparation. Act out the scene that takes place at a one-stop wedding exhibition.

Situation 4: Two travel mates are planning for a vacation in Indonesia. One of them suggests hiring the service of a travel agency to get the best offer while the other prefers to travel independently to save money. Act out the conversation that takes place at the office.

Situation 5: A class representative is discussing with is/her assistant on a plan to celebrate Teacher's Day for their teachers. One of them suggests organizing an appreciation party at a famous restaurant and the other plans to have a potluck party and celebrate it in a classroom. Act out the conversation that takes place in the classroom. 